\title{
La « vieille église » de Champagnole (Jura)
}

\author{
David Billoin
}

\section{(2) OpenEdition}

\section{Journals}

Édition électronique

URL : https://journals.openedition.org/cem/11879

DOI : $10.4000 /$ cem. 11879

ISSN : 1954-3093

Éditeur

Centre d'études médiévales Saint-Germain d'Auxerre

Édition imprimée

Pagination : 33-36

ISSN : 1623-5770

\section{Référence électronique}

David Billoin, «La « vieille église » de Champagnole (Jura) », Bulletin du centre d'études médiévales d'Auxerre | BUCEMA [En ligne], 15 | 2011, mis en ligne le 12 juillet 2011, consulté le 22 septembre 2022. URL : http://journals.openedition.org/cem/11879; DOI : https://doi.org/10.4000/cem.11879

Ce document a été généré automatiquement le 22 septembre 2022.

\section{(c) (i) (2)(2)}

Creative Commons - Attribution - Pas d'Utilisation Commerciale - Partage dans les Mêmes Conditions 4.0 International - CC BY-NC-SA 4.0

https://creativecommons.org/licenses/by-nc-sa/4.0/ 


\title{
La « vieille église » de Champagnole (Jura)
}

\author{
David Billoin
}

1 Un diagnostic archéologique réalisé en 2010 à l'emplacement de la «vieille église » de Champagnole, aujourd'hui disparue, a donné l'occasion de documenter cet édifice ${ }^{1}$.

2 Selon une tradition locale, la première église de Champagnole aurait été érigée aux $\mathrm{V}^{\mathrm{e}}$ $\mathrm{VI}^{\mathrm{e}}$ siècles, comme beaucoup d'autres édifices cultuels du Jura, sur une hauteur au nordouest de la ville et en bordure de la route reliant la ville à Poligny. Des tombes «païennes" sont supposées avoir été trouvées aux confins du cimetière attenant à l'église, lors de l'exploitation de graviers. Cette église n'est cependant attestée dans les textes qu'à partir du XII ${ }^{e}$ siècle, lorsque l'archevêque de Besançon donne, en 1130, une partie de l'église à l'abbaye de Balerne, qui détenait déjà l'autre part. Cet édifice reçoit les fidèles d'Ardon, de Sapois, de Cize, de Ney et d'Équevillon en partie, puisque ce village dépend, pour une part, de la paroisse de Saint-Germain. Une note rédigée avant sa démolition la décrit ainsi :

«(...) placée sur une hauteur, près d'un grand chemin au couchant du dit village duquel elle est éloignée de 1390 pieds, (...) le chœur de ladite église est fort bas, voûté en berceau ayant de longueur 21 pieds sur 15 de largeur (...). Le clocher est placé sur l'extrémité du chœur du côté du couchant. C'est une tour carrée ayant 12 pieds et demi (...). La nef de l'église n'est ni cadetée, ni voûtée. Il n'y a que des planches de sapin tant pour le plancher par terre que pour celui sur tête (...). »

3 Aucune représentation ne figure cet édifice de $8 \mathrm{~m}$ sur $28 \mathrm{~m}$ de longueur, incluant la tour du clocher et la sacristie. Peu à peu abandonnée et ruinée, elle est démolie après 1758, alors que des inhumations continuent d'être pratiquées de plus en plus sporadiquement dans son cimetière jusqu'en 1760 , au profit de la mise en service du cimetière de Chaudry de la nouvelle église intra muros.

4 Les vestiges de cette "vieille église » ont été, semble-t-il, complètement détruits par une exploitation de gravier d'après les observations de terrain, ce que confirme effectivement un procès-verbal daté du 23 mai 1893, condamnant l'entrepreneur exploitant le monticule occupé par l'église et son cimetière, « qui formait une couronne 
autour de l'édifice ». Cependant, une portion de $200 \mathrm{~m}^{2}$ environ du cimetière épargnée par ces travaux a pu être reconnue et cinq sépultures étudiées (fig. 1 et 2).

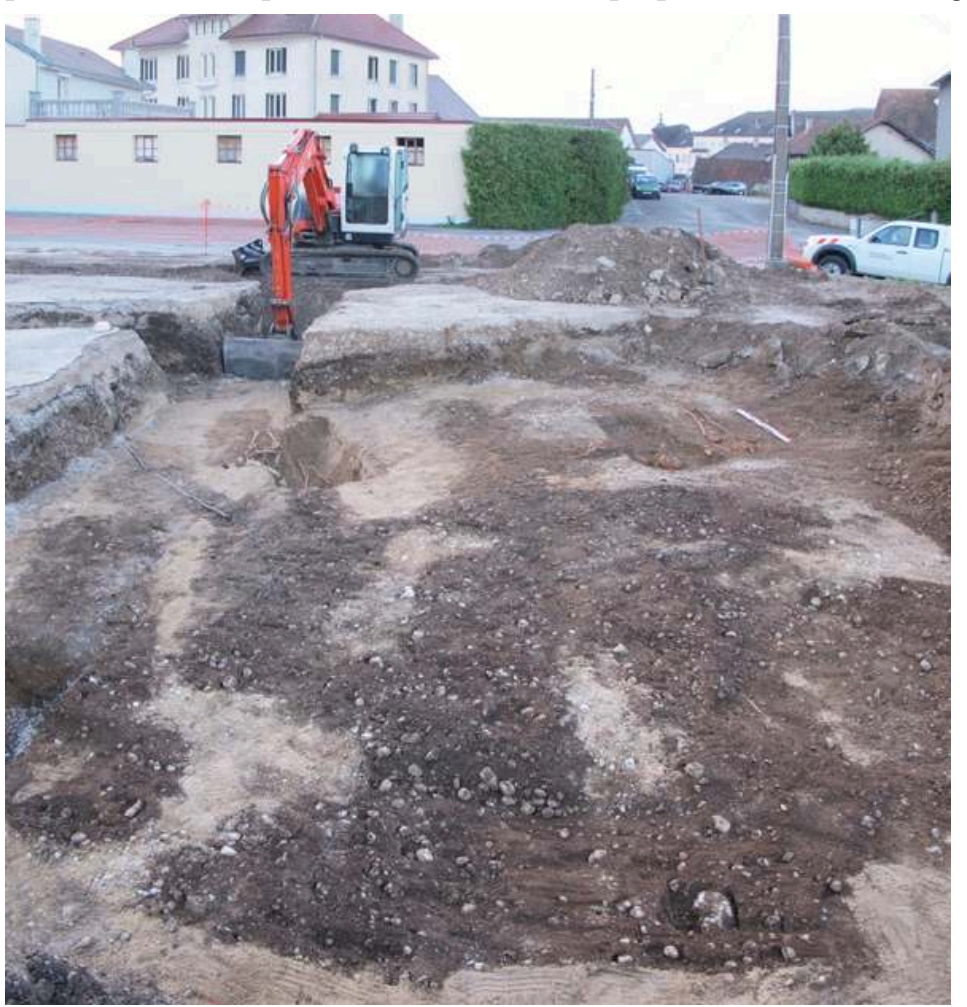

Fig. 1 - Champagnole, vue du cimetière en cours de dégagement (cl. D. Billoin, Inrap).

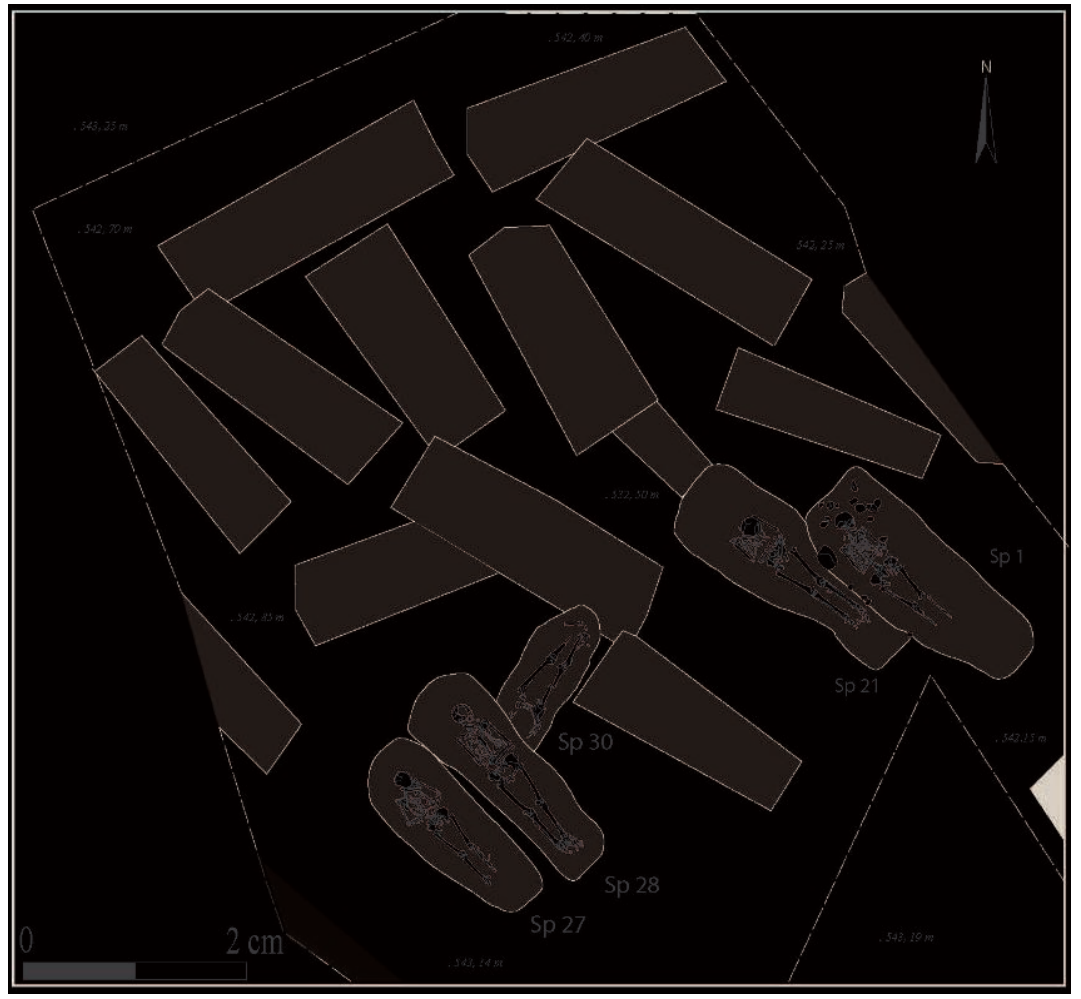

Fig. 2 - Champagnole, plan de la portion de cimetière épargné par l'exploitation de gravier (P. Haut, Inrap). 
Creusées dans un substrat sablo-graveleux d'origine fluvio-glaciaire, ces tombes révèlent une densité moyenne, occasionnant des recoupements entre elles et des différences d'orientations significatives. Assez standardisées et de forme légèrement trapézoïdale, les alvéoles funéraires apparaissent spacieuses, à contours assez évasés dus à la faible tenue de ce sous-sol. Les postures des corps sont également assez standardisées avec des variantes dans la position des membres supérieurs repliés sur le corps (fig. 3).

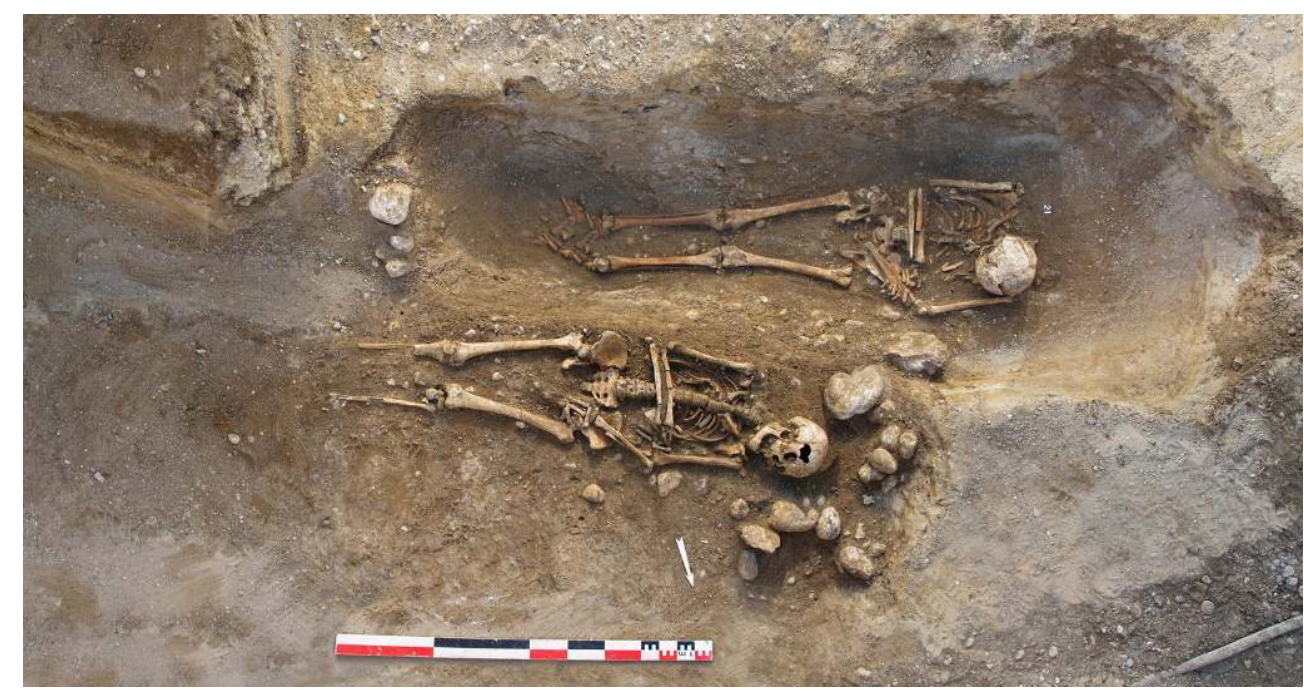

Fig. 3 - Champagnole, la sépulture $n^{\circ}$ Sp. 1 superposée partiellement à la sépulture n Sp. 21 (cl. D. Billoin, Inrap).

Du point de vue taphonomique, les nombreux indices de décomposition en espace vide indiquent l'utilisation de contenants en matériaux périssables, de type cercueil en bois chevillé (absence de clous), avec des contraintes linéaires et d'ajustements parfaitement visibles. L'absence de tout mobilier et l'emploi d'une architecture funéraire très commune et peu datable ont justifié une datation radiocarbone sur os d'une de ces sépultures ( $\mathrm{n}^{\circ}$ Sp. 21). La période de 781 à 979 apr. J.-C. (Ly-15453)est une date relativement précoce et l'on ignore s'il s'agit de la partie ancienne du cimetière ou non. Dans tous les cas, elle atteste la présence d'un édifice religieux à Champagnole dès cette époque, dont la première mention apparaît sous le terme de Campanola in pago scodiensium au $\mathrm{x}^{\mathrm{e}}$ siècle, mais dans un environnement archéologique très riche, dominé par le sanctuaire antique du Mont-Rivel.

\section{NOTES}

1. D. BILLoIN, Champagnole (Jura). Les Éclesches, le cimetière de la première église, rapport Inrap, 2010. 
INDEX

Mots-clés : église

Index géographique : France/Champagnole 